\section{Trophy hunting: Bans create opening for change}

In their Letter “Trophy hunting bans imperil biodiversity” (30 August, p. 874), A. Dickman et al. warn that banning trophy hunting, a practice many of them deem "repugnant," could threaten African biodiversity and livelihoods. What they actually describe is how loss of funding may impart these effects, without specifying any unique benefits of trophy hunting. It is defeatist to defend business-as-usual instead of promoting alternative conservation activities that could sustain formerly trophy-hunted species and areas.

Trophy hunting relies on deep geopolitical inequalities, particularly in Africa, where it often fails to deliver demonstrable conservation outcomes (1) and can intersect with crime (2). It yields low returns at household levels (3), with only a fraction of generated income reaching local communities (4). It also siphons off wildlife from adjacent protected areas (5), reduces population connectivity and resilience, and can have genetic consequences such as reductions in body, horn, and/or tusk size (6). Its effects on wildlife demography and behavior can be profound (7).

Trophy import bans present an opportunity to rethink how we can conserve wildlife in nonextractive ways that are consistent with shifting public opinion. The system is primed for change. The recently polled U.S. public shares attitudes with other countries enacting trophy import bans and especially strongly disapproves of trophy hunting of African elephants and lions (8). Sustainable alternatives exist and could reduce reliance on a small and narrowing cohort of wealthy Western “donors" (9).

For example, land use reforms, co-management, and greater participatory stewardship can provide a more sustainable, resilient, and equitable system (10). Locally adjusted and bottom-up management practices (11), granting communities land titles, conservation-compatible agriculture, and coexistence approaches can also benefit communities and conservation more than trophy hunting. In addition, tourism reforms could invigorate domestic tourism (12), minimize leakage of tourism income to foreign investors, and reduce the footprint of wildlife-viewing tourism through green development investment. Diversified nature-based tourism beyond photographing and viewing wildlife could incorporate survival skills/bushcraft training and agritourism, emphasizing local knowledge, cultural exchange, and inclusion of women. Finally, environmental investments could connect would-be micro-investors more directly to wildlife-wealthy communities. Financial strategies such as decentralized markets made possible by blockchain technology could use carbon and biodiversity credits for conserving habitats. Sustainable enterprise development could generate direct financial benefits to local communities.

During transitions, nongovernmental organizations could raise funds to pay concessions or countries could agree that a private entity would temporarily assume game reserve management. As the bans are not blanket but import bans, they provide the impetus and also the time to incrementally switch to practices that maximize contributions to the Sustainable Development Goals.

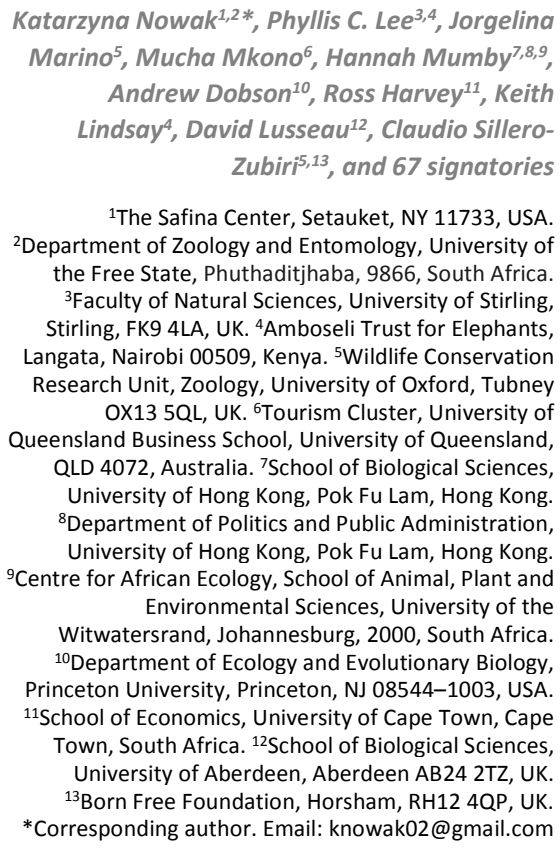

${ }^{1}$ The Safina Center, Setauket, NY 11733, USA. ${ }^{2}$ Department of Zoology and Entomology, University of the Free State, Phuthaditjhaba, 9866, South Africa. ${ }^{3}$ Faculty of Natural Sciences, University of Stirling, Stirling, FK9 4LA, UK. ${ }^{4}$ Amboseli Trust for Elephants, Langata, Nairobi 00509, Kenya. ${ }^{5}$ Wildlife Conservation Research Unit, Zoology, University of Oxford, Tubney OX13 5QL, UK. ${ }^{6}$ Tourism Cluster, University of Queensland Business School, University of Queensland, QLD 4072, Australia. ${ }^{7}$ School of Biological Sciences, University of Hong Kong, Pok Fu Lam, Hong Kong. ${ }^{8}$ Department of Politics and Public Administration, University of Hong Kong, Pok Fu Lam, Hong Kong.

${ }^{9}$ Centre for African Ecology, School of Animal, Plant and Environmental Sciences, University of the Witwatersrand, Johannesburg, 2000, South Africa. ${ }^{10}$ Department of Ecology and Evolutionary Biology, Princeton University, Princeton, NJ 08544-1003, USA

${ }^{11}$ School of Economics, University of Cape Town, Cape Town, South Africa. ${ }^{12}$ School of Biological Sciences, University of Aberdeen, Aberdeen AB24 2TZ, UK.

${ }^{13}$ Born Free Foundation, Horsham, RH12 4QP, UK.

*Corresponding author. Email: knowak02@gmail.com

REFERENCES AND NOTES

1. J. Selier et al., J. Wildlife Manage. 78, 122 (2014).

2.T. Milliken, J. Shaw, "The South Africa-Viet Nam Rhino Horn Trade Nexus" (TRAFFIC, 2012).

3.M. Segage, Master's thesis, University of Limpopo (2015).

4. I. Nordbø et al., J. Sustain. Tour. 26, 68 (2018).

5. A. J. Loveridge et al., Biol. Conserv. 134, 548 (2016).

6. D. W. Coltman et al., Nature 426, 655 (2003).

7. J. M. Milner et al., Conserv. Biol. 21, 36 (2007)

8. Responsive Management, “Americans' attitudes to

ward hunting, fishing, sport shooting and trapping" (NSSF, 2019); https://responsivemanagement.com/wp-content/uploads/2019/08/AmericansAttitudesReport.pdf.

9. C. Batavia et al., Conserv. Lett. 12, e12565 (2018).

10. IPBES, “IPBES global assessment summary for policymakers" (2019); www.ipbes.net/news/ipbes-global-assessment-summary-policymakers-pdf.

11. Z. T. Ashenafi, N. Leader-Williams, Hum. Ecol. 33, 539 (2005).

12. S. B. Mariki et al., J. Environ. Pol. Plan. 4, 62 (2011).

COMPETING INTERESTS

P.C.L. is Director of Science, Amboseli Trust for Elephants. R.H. consults for the Conservation Action Trust and the EMS Foundation. D.L. is a member of the IUCN SSC/CEESP SULi and IUCN SSC CSG. C.S.-Z. is Chair of the IUCN SSC Canid Specialist Group and Chief Scientist of Born Free Foundation.

SUPPLEMENTARY MATERIAL

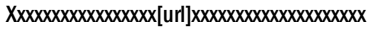

List of signatories

10.1126/science.aaz4135

SCIENCE VOL. xxx • galley printed 16 March, 2020 • • For Issue Date:??? 1 